\title{
The syntax of Dagbani personal pronouns: an analysis
}

\author{
Abukari Kwame \\ PhD Student in Interdisciplinary Studies \\ College of Graduate and Postdoctoral Studies \\ University of Saskatchewan \\ Saskatoon, Canada \\ Email: abukarikwames@yahoo.com
}

Submitted: November 16, 2018/ Accepted: June 17, 2019/ Published: December 30, 2019

\begin{abstract}
Cross-linguistically, personal pronouns are noted as being deficient in relation to some morphosyntactic and phonological properties. Some striking asymmetries have been identified between strong and weak personal pronouns in relation to modification, coordination/conjunction, whether they have a semantic referent, and can encode focus. This study explores the personal pronominal system of Dagbani along Cardinaletti and Starke's (1994) typology and observed asymmetries. Using insights from published literature on Dagbani pronouns as well as my understanding as a native speaker, I argue that, unlike personal pronouns in Romance/Germanic languages, Dagbani personal pronouns can be modified by quantifiers, can be coordinated, and can occur in conjunction constructions, as well as encode topic and focus as salient semantic discourse properties. Furthermore, the pre/post verbal distinctions among nonemphatic pronominal forms in Dagbani still hold, even as these occur in coordinated and modified constructions, due to structural constraints imposed on them by coordinating conjunctions and quantifiers.
\end{abstract}

Keywords: Dagbani, personal pronouns, pronoun coordination, structural deficiency, focus contexts

\section{Introduction}

Dagbani is a Gur language spoken in Northern Ghana and has three dialects with slight variations in tone and some lexical words (Hudu, 2010). Bodomo (1993) proposed that due to the sibling relationship that exists between Dagbani, Mampruli, Dagaare, and Kusaal, the term Mabia would better serve as a group label for this family of languages. Dagbani is an SVO language with very poor morphological markings. Grammatical roles (including case among nonemphatic pronouns) of arguments are influenced by syntax. Personal pronouns in Dagbani 
are often grouped into preverbal/postverbal, emphatic/nonemphatic, or weak/ strong pronouns (Purvis, 2007; Olawsky, 1999, 2002). Over the years, the pronominal system of the language has been the focus of some research, however, some disagreements in findings exist with regard to the syntax of personal pronouns. Whereas some studies on Dagbani personal pronouns use the pre/post verbal criterion (Olawsky, 2002) to examine the distribution of personal pronouns (particularly the nonemphatic/weak forms), others have used the grammatical case based on the functions pronouns play within a sentence or a DP (Issah, 2011, 2013). For instance, Olawsky (2002) claims that Dagbani pronouns offer a good example of what he calls "clitics". He has argued that, since the nonemphatic forms cannot bear stress or stand isolated as full prosodic units unless they are attached to a host phonological unit, these nonemphatic forms of personal pronouns qualify as proclitics. Olawsky has also proposed that the preverbal forms of nonemphatic pronouns are the unmarked forms. Purvis (2007), on the other hand, is of the view that the pre/post verbal notion is problematic. Instead, he offered a primarily phonologically motivated categorization of Dagbani personal pronouns based on processes of cliticization. Additionally, Purvis questioned the notion of emphatic/ nonemphatic labels, stressing that the terms "strong/weak" are better for the emphatic/nonemphatic pronouns, respectively. Furthermore, in studying reflexive pronouns and the structure of a simple noun phrase in Dagbani, Issah $(2011,2013)$ categorized nonemphatic pronouns according to grammatical case, putting them into nominative, accusative, and genitive pronouns.

Cross-linguistically, Cardinaletti and Starke (1994) have studied the pronominal classes of Romance and Germanic languages and offered some interesting descriptive generalizations based on the relationships between the classes of pronouns in these language families. Using morphological, semantic, distributional/syntactic, and phonological (prosodic) asymmetries, Cardinaletti and Starke demonstrated how strong and deficient pronouns in these languages differed. Striking asymmetries are noted in terms of c-modification and coordination, conjunction, having a semantic referent, and the ability to encode contrastive focus (detailed discussion of these will be provided in the following section) between deficient and strong personal pronouns.

My aim in this paper is to use Cardinaletti and Starke's (1994) typology/ model to examine how far Dagbani personal pronouns pattern with the properties and asymmetries identified in their study. Using my native speaker intuition as well as published papers on Dagbani, particularly that of Purvis (2007), I intend to provide a broader descriptive picture of Dagbani personal pronouns in terms of the morphosyntactic differences between emphatic and nonemphatic pronouns. 
Furthermore, I aim to contribute to knowledge on the pre/post verbal categorization of Dagbani personal pronouns, especially in relation to conjunction and quantifier modification. This paper is structured as follows: The next section covers a summary of the main issues discussed in Cardinaletti and Starke (1994) to lay the foundation for the discussion of Dagbani personal pronouns. In this segment, I present the salient distributional differences between strong and deficient pronouns in Romance and Germanic languages as observed by these authors. This is followed an account of the personal pronouns of Dagbani. Both emphatic and nonemphatic pronouns will be stated and a brief description of them provided in terms of their structural differences as well as previous distributional notions about them. After that, I discuss Dagbani personal pronouns according to some of the criteria used in Cardinaletti and Starke (1994). In this part, the Dagbani personal pronouns are discussed in line with their ability to exhibit some of the asymmetries noted in Cardinaletti and Starke (1994) such as: conjunction and modification, containment (the structural relationship between the two sets of pronouns), pre/post verbal occurrences, and their ability to serve as topic or focus in sentences. I then provide an attempted syntactic account on pronoun coordination and modification. Finally, I summarize the main issues raised in this paper and draw my conclusions.

Before I proceed to the next section, I would like to make a few terminological observations. When I refer to the sets of Dagbani personal pronouns, I maintain the emphatic and nonemphatic labels so that references to the personal pronouns in Romance/Germanic languages still retain the labels used in Cardinaletti and Starke (1994). Hence, when the labels "weak", "strong", and "clitics" are used, they refer to the personal pronouns as used in Cardinaletti and Starke's study. Also, where a cited source makes use of these terms in relation to Dagbani personal pronouns, a notification is made.

Before I proceed to the next section, I would like to make a few terminological observations. When I refer to the sets of Dagbani personal pronouns, I maintain the emphatic and nonemphatic labels so that references to the personal pronouns in Romance/Germanic languages still retain the labels used in Cardinaletti and Starke (1994). Hence, when the labels "weak", "strong", and "clitics" are used, they refer to the personal pronouns as used in Cardinaletti and Starke's study. Also, where a cited source makes use of these terms in relation to Dagbani personal pronouns, a notification is made. 


\section{Asymmetries in personal pronouns in Cardinaletti and Starke's (1994) study}

Several asymmetries have been noted in the phonology, morphology, syntax, and semantics of personal pronouns in Romance and Germanic languages in Cardinaletti and Starke's study, The Typology of Structural Deficiency (1994). These asymmetries are outlined in this section and then later referred to when Dagbani personal pronouns are discussed.

Morphologically, Cardinaletti and Starke (1994) observed that class 2 personal pronouns (deficient forms) are systematically reduced with respect to class 1 (strong) personal pronouns in both Romance and Germanic languages (1).

(1) Deficient pronouns have reduced forms relative to strong pronouns

\section{Deficient form}

(a) loro

(b) ho

$\mathrm{mu}$

\section{Strong form}

a-loro (to them)

Italian

je-ho

je-mu (him)
Slovak

The data in (1) suggests that the deficient forms may be contained within the strong forms or are morphologically reduced in form in relation to the strong pronouns.

Additionally, Cardinaletti and Starke maintained that class 2 (deficient) pronouns cannot be coordinated, but that they can refer to both human and nonhuman referents, whereas class 1 pronouns (the strong forms) may be coordinated. However, their interpretation will be limited to only human referents, as in (2).

(2) Coordination in personal pronouns (Cardinaletti and Starke, 1994, p. 43)

$$
<+ \text { human }><\text {-human }>
$$

German ( $€$ Germanic)
(a) Sie sind groß
Sie und die daneben sind groß

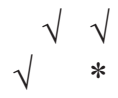
they and those besides are tall/big

Gun (€ Kwa)

Yélè yon wankpè

(d) Yélè kpo yélè kpo yon wankpè

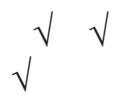

She and she and know beauty 
In (2a), the pronoun sie, when used as a deficient pronoun in German, cannot occur in a coordinated structure. However, in such a context, it can refer to both human and non-human referents. On the other hand, in (2b), where sie is used as a strong pronoun, it can occur in a coordinate structure. However, the nonhuman interpretation is lost even though, morpho-phonologically the shape of the pronoun does not change. The same pattern applies in the Gun data in (2c, d). In the languages in (2), as well as in many other Romance languages, Cardinaletti and Starke indicated that only strong pronouns can occur in coordinated syntactic structures, and that in such structures they can refer only to human entities $(2 b, d)$.

Based on syntax, Cardinaletti and Starke opined that deficient pronouns have a restricted distribution relative to strong pronouns. Firstly, they maintained that deficient pronouns cannot occur in a base-generated or theta $(\theta)$ position, but strong pronouns can occur in these positions, as shown in (3). Secondly, deficient pronouns cannot occur in peripheral positions, such as in clefts, left/right dislocation, or in isolation, as shown in the Italian data (4). They further observed that this pattern cuts across several languages, such as the behaviour of Dutch het ('it'), Slovak $\boldsymbol{m i}$ ('to me'), and English it (p. 47).

(3) Positional restriction of deficient and strong pronouns (Cardinaletti and Starke, 1994, p. 46)

$\left\{\right.$ essa- $_{\mathrm{D}}$; lei $\mathrm{S}_{\mathrm{S}}$; Maria $\}$ forse l'ha fatto $\left\{{ }^{*}\right.$ essa- $_{\mathrm{D}}$; lei ${ }_{\mathrm{S}}$; Maria $\}$ da sola It- $_{\mathrm{D}}$; she $_{\mathrm{S}}$; Mary may be it-has done DA alone

(4) Deficient pronouns and peripheral positions (Cardinaletti and Starke, 1994, p. 47)

(a) $E^{\prime}\left\{{ }^{*}\right.$ essa- $_{D} ;$ lei $_{\mathrm{S}} ;$ Maria $\}$ che è bella (cleft)

It is $\left\{* 3 \mathrm{Sg} . \mathrm{fm}_{-}{ }_{\mathrm{D}} ; 3 \mathrm{Sg} . \mathrm{fm}_{-\mathrm{S}}\right.$; Mary $\}$ that is pretty.

It is Mary that is pretty.

(b) $\left\{\right.$ *essa- $_{\mathrm{D}}$; lei $\mathrm{S}_{\mathrm{S}}$; Maria $\}$, lei è bella. (left dislocation)

$\left\{* 3 \mathrm{Sg} . \mathrm{fm}_{-}\right.$; $3 \mathrm{Sg} . \mathrm{fm}_{\mathrm{S}}$; Mary $\}$, she/it is pretty

She/it is pretty.

(c) pro arriverà presto, $\left\{{ }^{*}\right.$ essa- $_{\mathrm{D}} ;$ lei- ${ }_{\mathrm{S}} ;$ Maria $\}$. (right dislocation) pro will arrive soon, $\left\{* 3 \mathrm{Sg} . \mathrm{fm}_{-}{ }_{\mathrm{D}} ; 3 \mathrm{Sg} . \mathrm{fm}_{-}{ }_{\mathrm{S}}\right.$; Mary $\}$.

She/it will arrive soon.

(d) Chi è bella? $\left\{{ }^{*}\right.$ essa- $_{\mathrm{D}}$; lei- ${ }_{\mathrm{S}}$; Maria $\}$. (isolation)

Who is pretty? $\left\{* 3 \mathrm{Sg} . \mathrm{fm}_{-}\right.$; $33 \mathrm{Sg} . \mathrm{fm}_{-}^{-}$; Mary $\}$.

Cardinaletti and Starke explained that the deficient pronoun essa in Italian cannot occur in a base position, as signalled by the [*] marking. Hence, deficient forms can only occur in a specially-derived position. In (4a-c), it is shown that the 
Italian deficient pronoun essa cannot occur in cleft, left or right dislocation, or stand alone as an answer to a wh- question, as in (4d). Note that $\left[{ }_{-}\right]$stands for a deficient pronoun whereas $\left[-{ }_{\mathrm{S}}\right]$ indicates that the pronoun is a strong one.

Furthermore, Cardinaletti and Starke (1994) proposed that, semantically, deficient pronouns must have an antecedent which is already prominent in the discourse, as illustrated by the data in (5). Note that ostension (accompanying gesture) can be used to establish discourse saliency, as shown in the data by the arrow, suggesting that deficient pronouns must refer to discourse prominent antecedents.

(5) Deficient pronouns and discourse prominence (Cardinaletti and Starke, 1994, p. 49)

(a)

*J'ai vu Marie puis je $\rightarrow$ l' ai vu

$\sqrt{ }$ J'ai vu Marie puis j' ai vu $\rightarrow$ elle.

I have seen Mary then I her have seen her

(b) $\sqrt{ }$ Mets- toi içi et regardes cette maison. To $\rightarrow$ la vois bien maintenant?

Come here and look at this house. You it see well now?

Come here and look at this house. Can you see it well now?

(c) $\sqrt{ }$ Mais, tu ne vois donc pas ce livre? Bien sûr que je $\rightarrow$ le vois

But, you don't see this book? Of course that I it see

But don't you see this book? Of course I see it.

Based on (5), Cardinaletti and Starke claimed that "the deficient elements are permissible with contrastive stress and ostension, only if they refer to an entity which is 'already prominent in the discourse" (emphasis in original) (p. 49). Accordingly, they argued that (5a) is impossible, to the extent that both contrastive focus and ostension refer largely to a non-prominent entity in the discourse. However, in $(5 \mathrm{~b}, \mathrm{c})$, the prominent topic of the discourse serves as the referent of the deficient pronouns $\boldsymbol{l a}$ and $\boldsymbol{l} \boldsymbol{e}$. In the same vein, Cardinaletti and Starke added that in both expletive and impersonal (non-referential) contexts/constructions, personal pronoun subjects must be deficient, since strong pronouns are uninterpretable in such constructions.

Prosodically, it is argued that strong pronouns and lexical nouns are able to form a single prosodic unit, whereas for deficient pronouns, they must be adjacent to a lexical element. This means that they cannot function as a prosodic unit in isolation. Furthermore, Cardinaletti and Starke observed that only deficient pronouns may undergo reduction phenomena. 
In summary, the major asymmetries noted by Cardinaletti and Starke (1994) and further highlighted in Grohmann (2000) in relation to the personal pronouns in Romance and Germanic languages are that deficient pronouns are reduced with reference to strong ones, and can only occur in surface structures in a speciallyderived position. This means that deficient pronouns cannot occur in a basegenerated position under the VP, dislocated, or in cleft structures. Also, deficient pronouns cannot be coordinated and c-modified and that, where possible, deficient pronouns are preferred over strong ones. Furthermore, deficient pronouns are the only forms that can prosodically restructure, for example, can undergo contraction/ reduction or liaison. Finally, deficient pronouns can refer to both human and nonhuman referents in a discourse, and can also be used in expletive and impersonal constructions, whereas strong pronouns make reference to only human entities, and can bear their own range-restriction by serving as discourse prominent antecedents (such as acting as contrastive focus and/or ostension - signal gesture).

Cardinaletti and Starke, however, argued strongly against some historical notions about weak pronouns. They postulated that, due to what appears to be a historical accident, the inaccurate generalization that deficient pronouns cannot be stressed has come to be seen as a fundamental property of deficient elements (1994, p. 56). Consequently, the fact that deficient pronouns do not occur coordinated, modified, or with ostension has been linked to the notion that they mostly occur unstressed. To contest these notions, Cardinaletti and Starke (1994, p. 57) provided several examples of counter-evidence to show that deficient elements can be stressed (e.g. in essi vanno in chiesa ('they go to church'), with essi being stressed) in Italian, and can also bear contrastive focus when discourse conditions are satisfied. They also noted that in Gun, a Kwa language in Africa, some strong pronouns may also occur unfocused, which supports their argument that deficient pronouns are not always prosodically inert.

To account for the distributional variations between strong and deficient pronouns, Cardinaletti and Starke (1994) proposed that there is a structural deficiency among weak pronouns. Accordingly, a three-class system is proposed where deficient pronouns are further grouped into weak (mildly deficient pronouns) and clitic (severely deficient pronouns) forms. They indicated that some structural containment relationship is obtained between the weak and strong pronouns, for example, as in (6), and between the weak and clitic pronouns, as demonstrated in (7). 
Abukari, K./Legon Journal of the Humanities Vol. 30.2 (2019)

(6) Containment relationship between weak and strong pronouns (Cardinaletti and Starke, 1994:70)
(a) Strong:
je-ho
je-mu
a-loro
(b) Deficient:
ho
$\mathrm{mu}$
loro
him.
Slovak
to.him. Slovak
to.them.
Italian

(7) Containment relationship among all the three pronouns (Cardinaletti and Starke, 1994:67).

clitic

(a) $\mathrm{s}<$

il $=$

(b) ho $<$ weak

es

il

jeho

loro

il

sie strong

(Olang Tirolean)

(French)

(Slovak)

a loro (Italian)

lui (French)

sie (German)

In both (6) and (7) the structural relationship among all pronominal forms is shown, where clitics are contained in the weak forms, while the weak forms are also contained in the strong forms. Yet, it is supposed that some morphemes are missing in these patterns, hence the proposal that, in terms of morphology, a clitic can be smaller or the same as a weak form, and a weak form can also be smaller or the same as a strong form, as in (8).

(8) $\quad$ clitic $\leq$ weak $\leq$ strong

To explain the difference in structure and function, Cardinaletti and Starke argued that both weak and clitic pronouns lack the CP functional head in their projections. As a result, to compensate for this, and in order to ensure specifierhead agreement, derivation must apply for these deficient forms to function well at the surface level. The detailed syntax involved in the specificier-head agreement derivation, as demonstrated by Cardinaletti and Starke (1994), will not be covered in this paper.

Having given a summary of the main issues that Cardinaletti and Starke discussed concerning the nature and distribution of personal pronouns in Romance and Germanic languages, the next section of this paper will present the Dagbani personal pronouns and review them alongside the proposals as outlined by Cardinaletti and Starke (1994). 


\section{Dagbani personal pronouns}

Dagbani personal pronouns have been grouped into different sets based on either grammatical functions or syntactic distribution in sentences in relation to the verb (Issah, 2011, 2013; Olawsky, 2002). As Purvis (2007) observes, the set of emphatic pronouns in Dagbani has generally been accepted as one distinct set with little dispute or confusion about their description and possible distribution. However, nonemphatic pronouns have not only proved to be difficult to describe, but they also constitute a source of debate among researchers. The description and distribution of this set of pronouns have often been done in relation to the verb, as either pre/post verbal or as subject/object in function. The emphatic pronouns and the nonemphatic ones are presented below

\section{Emphatic personal pronouns in Dagbani}

Personal pronouns in Dagbani mark only person, number, and animacy. These pronouns do not mark gender, unlike third person forms in other languages with very rich morphology, or as in English. Purvis (2007) claimed that Dagbani emphatic personal pronouns are not marked for a grammatical role or for any other function, which means that they can assume any grammatical role in sentences. Further, he observed that emphatic pronouns can be represented in their non-elided forms, suggesting that Dagbani emphatic pronouns have their full forms and elided/ truncated forms ${ }^{1}$ (for example; mani vs. man' and yuna vs. yun'), both of which can occur in sentences. Another interesting observation that Purvis made about Dagbani emphatic pronouns is that they can be coordinated or adjoined freely with many other lexical nouns or pronouns. The set of Dagbani emphatic pronouns are presented in Table 1 in (9).

(9) Table 1: The set of emphatic pronouns in Dagbani (Purvis, 2007:240)

\begin{tabular}{|l|l|l|}
\hline \multicolumn{1}{|c|}{ Person/Number } & \multicolumn{2}{c|}{ Singular Plural } \\
\hline 1st person & mani (man') & tinima (tinim') \\
\hline 2nd person & nyini (nyin') & yinima (yinim') \\
\hline 3rd person [+animate] & yuna (yun') & $\begin{array}{l}\text { bana, banima } \\
\text { bannima (bannim') }\end{array}$ \\
\hline 3rd person [-animate] & dina (din') & yana (yan') [dinnima] \\
\hline
\end{tabular}

Table 1 in (9) shows the truncated forms of each pronoun in parenthesis beside the untruncated ones. As Purvis argued, the plural form of the 3rd person inanimate pronoun in recent times is [dinnima] ${ }^{2}$. The forms [yana, yan' or yannima] were ${ }^{1}$ A reviewer pointed out that, this is not surprising since final vowel deletion in emphatic personal pronouns is a common phonological phenomenon in Mabia languages.

${ }^{2}$ A reviewer observed that pointed the form [din-nima] seem more uniform and transparent since it contains [-ma] or the default plural marker [-nima], which seems a general plural suffix of emphatic pronouns. Nonetheless, whether speakers prefer this form 
all attested to in the Western dialect (Tomosili) of Dagbani spoken in communities around Tamale. However, I am not sure if these forms are still very actively used in the Tomosili dialect. Also, in the plural forms of the 3rd person animate pronoun, the form [banima] is an interrogative pronoun (i.e. 'which people') rather than an emphatic pronoun. The emphatic form of that pronoun is [bannima], which is also noted by Issah (2013) in his analysis of Dagbani simple noun phrases. Again, the form [bena] is also attested to as a 3rd person animate plural pronoun, in the Nayahili dialect of Dagbani.

\section{Nonemphatic personal pronouns of Dagbani}

Like the emphatic pronouns, the nonemphatic personal pronouns also mark person, number, and animacy features, with the last feature restricted to only the 3rd person forms. As pointed out earlier, different arguments have been made about this set of personal pronouns in terms of their sentential distributive properties. Issah (2011) grouped these pronouns into nominative, accusative, and genitive forms, while Olawsky (1999, 2002) categorized them into preverbal and postverbal forms. However, Purvis (2007) claims that, a closer look at these pronouns reveals that the variation in opinion among scholars appeared to be based on structural and grammatical considerations influenced by the subject/object grammatical case distinctions made in English or other similar languages. Accordingly, Purvis believed that this categorization of Dagbani nonemphatic pronouns by educated Dagbani speakers is due to the influence of English grammar. A list of nonemphatic pronouns is presented in Table 2 in (10), as taken from Olawsky (1999, p. 22), but with some modifications.

(10) Nonemphatic pronouns

(a) Table 2: Dagbani nonemphatic personal pronouns

\begin{tabular}{|c|c|c|c|c|c|c|}
\hline \multirow[t]{2}{*}{ Person } & \multicolumn{3}{|l|}{ Singular } & \multicolumn{3}{|l|}{ Plural } \\
\hline & preverbal & unmarked & postverbal & preverbal & unmarked & postverbal \\
\hline 1st person & $\mathrm{n} / \mathrm{y} / \mathrm{m}$ & & $\mathrm{ma}$ & {$[\mathrm{ti}]$} & $\mathrm{ti}$ & {$[\mathrm{ti}]$} \\
\hline 2nd person & & $\mathrm{a}$ & & yi [yi்] & & ya \\
\hline $\begin{array}{l}\text { 3rd person } \\
{[+ \text { animate }]}\end{array}$ & & o & & $\mathrm{b} \varepsilon[\mathrm{bi}]$ & & $\mathrm{ba}$ \\
\hline $\begin{array}{l}\text { 3rd person } \\
\text { [-animate] }\end{array}$ & di [di] & & li & di [di] & (ya) & li \\
\hline
\end{tabular}

over others is an empirical question. 
Abukari, K.The Syntax of Dagbani personal pronouns: an analysis

(b) be chay- $\varnothing$ puu-ni.

3P1.Prev go-Perf farm-Loc

They have gone to the farm.

(c)

$\begin{array}{llll}\text { Adam } & \text { ti- } \varnothing & \text { ba } & \text { pini. } \\ \text { Adam } & \text { give-Perf } & \text { 3P1.Postv } & \text { gift. } \\ \text { Adam gave them a gift. } & & \end{array}$

For illustration, $(10 \mathrm{~b}, \mathrm{c})$ shows the pre/post verbal occurrence of some of the pronouns in Table 2. This issue will be taken up later in relation to the argument that the pre/post verbal distinction is not strict, since Purvis (2007) argued that postverbal pronouns can occur in preverbal positions and vice versa in sentences.

Furthermore, in Table 2 (10a), the preverbal form of the 1st person singular [n] is homorganic and gets assimilated to the place of articulation of the following stop sounds and may thus surface as $[\mathbf{n}, \mathbf{m}, \mathbf{n}]$. Phonologically, Olawsky $(1999,2002)$ observed that the structure for most of these pronouns is that they contain a consonant and a schwa-like vowel which appears in the orthography as $<\mathrm{i}>$. Accordingly, he proposed that if those pronouns are seen as containing an epenthetic schwa, then their forms will be /d/, /l/, /t/, and /b/ for [di], [li], [ti] , and [bi] respectively. This explains why the other forms of these pronouns are in square brackets in Table 2 with the muted - $\mathrm{i}[\mathrm{i}]$.

Another interesting observation about the nonemphatic pronouns is that the singular form of the 2 nd person pronoun is the same in both preverbal and postverbal positions, as is the 3rd person animate form. Also, the plural form for the 1 st person pronoun is the same in the pre/post verbal forms, while there is number syncretism for the 3rd person inanimate forms. These pronouns with identical morphemes either in their pre/post verbal forms or in their singular and plural forms will have some implications concerning their distribution in sentences as well as in coordinated structures, as I will show subsequently. For a clearer picture, the set of nonemphatic pronouns in (10) are repeated in (11), below, with the identical ones noted in boldface. 
(11) Non-emphatic pronouns which are identical in form

\begin{tabular}{lllll}
\multicolumn{3}{c}{ Singular forms } & \multicolumn{2}{c}{ Plural for } \\
& Prev. & Postv. & Prev. & Po \\
1st & $\mathrm{n}$ & ma & ti & ti \\
2nd & a & a & yi & ya \\
3rd & o & o & be & ba \\
& di & li & di & li
\end{tabular}

Given that the nonemphatic pronouns noted in (11) are the same, it is difficult to tell which form of the 1st plural, the 2nd singular, and 3rd person singular pronouns are preverbal, and which are postverbal, as well as which of them can occur in subject or in object positions. Further discussion of this will be presented in the following section. Note also that the $3 \mathrm{rd}$ person animate pronouns in the final row have no distinction between their singular and plural forms.

Having outlined the two sets of personal pronouns in Dagbani, I shall explore these pronouns along the lines proposed by Cardinaletti and Starke (1994). I will examine the relationship between the two sets of pronoun types, concerning their ability to conjoin, to be modified, to be focused, to be used as topics, and whether there is any containment relationship between them.

\section{Preverbal forms in post verbal positions and vice versa}

It has been observed that the preverbal forms of the nonemphatic pronouns can occur in postverbal positions while the postverbal forms can also occur in preverbal positions. However, the data in (12) seem to suggest otherwise.

(12) Personal pronouns and their positional restrictions in Dagbani
(a)
Yakubu ti-Ø
ma
pini.
Yakubu give-Perf
Yakubu gave me a gift.
(b)
Abu tu- $\varnothing$
1Sg.Postv.Nonemph
gift.Sg
Abu
ba
pam.
Abu insulted them so much.
(c)
*ti
ti- $\varnothing$
be
nimdi.
2P1.Prev.Nonemph give-Perf 3P1.Prev.Nonemph meat We gave them meat.
(d)

$\begin{array}{lrlll}* \text { ma } & \text { chay- } \varnothing & \text { puu } & \text { maa ni zuyo. } \\ \text { 1Sg.Postv.Nonemph } & \text { go-Perf } & \text { farm } & \text { Def } & \text { Loc today } \\ \text { I went to the farm today. } & & \end{array}$


In (12a), the postverbal form of the 1st singular pronoun is used while in (12b) the postverbal form of the 3rd person plural form is used. Both forms occur in postverbal positions, which is why the sentences are grammatically correct. However, (12c, d) are ungrammatical because the preverbal form [be], the 3rd person plural, is used in a postverbal position, rather than the postverbal form [ba], and in (12d) the postverbal form of the 1st person singular, [ma], is used in a preverbal position instead of the preverbal form $[\mathbf{n}]$. These sentences show that the preverbal forms cannot be used in a postverbal position except in conjunction or quantified phrases.

\section{Exploring Dagbani pronouns based on Cardinaletti and Starke's (1994) typology}

Based on the summary regarding the nature of personal pronouns in Romance and Germanic languages presented earily in the paper, this section will explore Dagbani personal pronouns along those asymmetries to determine how well they pattern with the generalisations noted by Cardinaletti and Starke. Basic similarities and differences will be noted as I explore the personal pronouns of Dagbani.

\section{Containment relationships between Dagbani personal pronouns}

Using insights from Cardinaletti and Starke (1994), I will say that the relationship between nonemphatic and emphatic personal pronouns involves some form of containment. Table 3 in (13) shows both the nonemphatic and emphatic personal pronouns of Dagbani. In order to explore the containment proposal of Cardinaletti and Starke, I divide each emphatic pronoun into two morphemes (base forms + suffixes) to determine whether they pattern with observations made by Cardinaletti and Starke regarding deficient/strong pronouns in their study.

(13) Table 3: The combined emphatic and nonemphatic personal pronouns

\begin{tabular}{|l|l|l|l|l|l|l|}
\hline Person & \multicolumn{4}{l|}{ Nonemphatic pronouns } & \multicolumn{2}{l|}{ Emphatic pronouns } \\
\hline & Singular forms & \multicolumn{2}{l|}{ Plural forms } & Singular & Plural \\
\hline & Prev & Postv & Prev & Post & & \\
\hline 1st person & n & ma & ti & ti & ma-ni & ti-nima/tinim' \\
\hline 2nd person & a & a & yi & ya & nyi-ni & yi-nima/yinim' \\
\hline $\begin{array}{l}\text { 3rd person } \\
\text { [animate] }\end{array}$ & o & o & be & ba & yu-na & $\begin{array}{l}\text { ba-na, } \\
\text { ban-nima }\end{array}$ \\
\hline $\begin{array}{l}\text { 3rd person } \\
\text { [-animate] }\end{array}$ & di & li & di & li & di-na & $\begin{array}{l}\text { din-nima/ } \\
\text { din-nim, }\end{array}$ \\
\hline
\end{tabular}


A closer look at the forms between nonemphatic and emphatic pronouns seems to indicate that there is some amount of containment relationship. In the 1st person pronoun forms, we could have [ma] contained in [ma-ni] and [ti] contained in [ti-nima], and same for the 3rd person inanimate forms [di] in [di-na] and [dinima]. The 2 nd and 3 rd person singular animate forms (marked in grey in Table 3 ) are monosyllabic in structure. However, their plural forms also seem to show some kind of containment relationship with their emphatic counterparts. The 2 nd person form [yi] is contained in [yi-nima], the 3rd person forms [be/ba] are contained in [ba-na] or [ban-nima], and the 3rd person inanimate form [di] is also contained in the emphatic form [di-na] or [din-nima].

Based on the above, it would appear that the singular forms of the emphatic pronouns are realised as [ma-] and [nyi-] plus some suffix [-ni] for the 1st person and 2nd person pronouns, while the 3rd person forms have [yu-] and [di-] plus a suffix [-na] for the animate/inanimate forms. Nonetheless, this segmentation does not produce any meaningful forms in Dagbani. Also, it is difficult to provide an explanation as to how the singular forms of the $2 \mathrm{nd}$ [a] and $3 \mathrm{rd}[\mathbf{o}]$ nonemphatic pronouns change into the emphatic forms [nyi-ni] and [nu-na], respectively. The plural emphatic forms, on the other hand, take the plural forms of the nonemphatic pronouns and add the suffix [-nima] or its shortened form [-nim'] to form the plural emphatic pronouns. Given that [-nima] is a default plural marker for some nouns, including loans (Olawsky, 1999, p.93), it makes sense to segment it as a number morpheme in these pronominal forms. Hence, the nonemphatic forms [ti, yi, be, di] are contained in the emphatic forms [tinima, yinima, bannima, dinnima], respectively.

Two patterns are observed in Table 3. First, there are inconsistencies in the morphological shape of the singular nonemphatic pronouns and their singular emphatic counterparts; therefore, they defy the establishment of any containment relationship. Second, the plural forms of the nonemphatic pronouns show a containment relationship with their plural emphatic counterparts. Therefore, comparing the relationship between the emphatic/nonemphatic pronouns in Dagbani to those of the strong/weak pronouns in Cardinaletti and Starke's study, I cannot conclusively argue that Dagbani personal pronouns pattern exactly with the structural relationships that exist between strong/weak pronouns in Cardinaletti and Starke (1994), although some form of containment can be seen between the plural forms of the emphatic/nonemphatic pronouns in Dagbani. 


\section{Dagbani personal pronouns and conjunction}

Purvis (2007, p. 241) observed that emphatic pronouns can be coordinated with other nouns and pronouns, examples of which are presented in (14).

(14) Coordinated emphatic personal pronouns

$\begin{array}{llllll}\text { (a) Yisa } & \text { ni } & \text { nyini } & \mathbf{n} & \text { yen } & \text { chay. } \\ \text { Yisa } & \text { Conj. } & \text { 2Sg.Emph } & \text { Foc } & \text { will } & \text { go }\end{array}$

Yisa and you will go.

(b) nyini ni mani ka yeligu. 2Sg.Emph Conj. 1Sg.Emph NEG say

You and I have no say.

(c) yuna ni yinima, ninvu?-yo-ya $\mathbf{n}$ nyen ya. 3Sg.Emph Conj. 2P1.Emph, person-bad-P1 Foc be 3P1.

Nonemph

he/she and you, you are bad people.

In these sentences, (14a) indicates that we can have a noun conjoined with an emphatic pronoun. In $(14 b, c)$, we have emphatic pronouns in a coordinate structure. However, these forms seem to be marked and if the pronoun is not in a focused context the nonemphatic forms may be preferred. For instance, (14a, b, and c) could be uttered as (15a, b, and c), respectively, with nonemphatic pronouns. For naturalness in speech, the forms in (15) are preferred over those in (14), which seems to suggest that the nonemphatic forms in Dagbani pattern with the deficient pronouns in a way described by Cardinaletti and Starke $(1994$, p. 46) that, where possible, deficient pronouns are preferred over strong ones. Thus, even though both emphatic and nonemphatic pronouns in Dagbani can be coordinated, the nonemphatic pronouns are preferred.

(15) Nonemphatic personal pronouns in coordinate structures.

(a) a mini Yisa $\mathbf{n}$ yen chay. 2Sg.Nonemph Conj Yisa Foc will go You and Yisa will go.

(b) $\mathrm{m}$ mini a ka yeligu. 1Sg.Nonemph Conj. 2Sg.Nonemph NEG say I and you have no say.

(c) a mini o, ninvuy-yo-ya n nyen ya. 2Sg.Nonemph Conj. 3Sg.Nonemph person-bad-Pl Foc be $2 \mathrm{Pl}$.

You and he/she, you are bad people.

Nonemph 
Abukari, K./Legon Journal of the Humanities Vol. 30.2 (2019)
(d) Yisa
$\operatorname{mini} a$
n
yen
chay.
Yisa
Conj.
You and Yisa will go.

From (15) above, it is obvious that the nonemphatic pronouns can also be coordinated with lexical nouns or with other nonemphatic pronouns. However, the occurrence of the 2 nd and 3rd person singular forms [a] and [o] do not settle the pre/post verbal debate, since they are the same in either position, as already noted in Table 3 in (13). Also, two emphatic pronouns can be conjoined with [bee] ('or') in cases of yes/no questions, where falling intonation is used, as in (16).

(16) Two emphatic pronouns in a coordinate structure

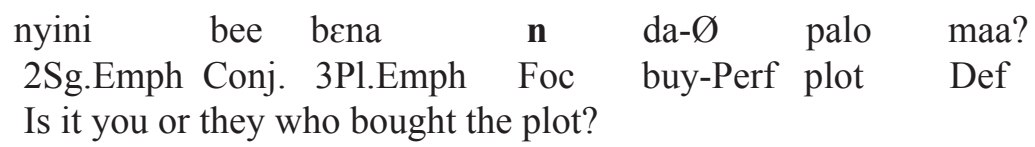

Another important factor in examples (14) - (15) is the presence of the focus head in addition to the conjunction markers, as I will discuss later.

Furthermore, nonemphatic personal pronouns in Dagbani can also occur in coordinate structures, as shown in (17).

(17) Conjoined nonemphatic personal pronouns
(a)
[Adam mini ba]
Adam and 3P1.Nonemph $\begin{array}{ll}\text { chan- } \varnothing & \text { puu-ni } \\ \text { go-Perf } & \text { farm-Loc }\end{array}$
Adam and them have gone to the farm. (Adam has gone to the farm with them)
$\begin{array}{lllll}\text { [N mini ya] } & \text { ni } & \text { chan- } \varnothing & \text { Tamale dali. } \\ \text { 1Sg.Nonemph } & \text { Conj. } & \text { 2Pl.Nonemph } & \text { Fut go-Perf } & \text { Tamale a day after }\end{array}$ tomorrow
I and you will go to Tamale a day after tomorrow. (I will go to Tamale with you...)
(c) Doo maa ti- $\varnothing$ [yi mini ba $]$ li?iri.
Man Def give-Perf 2Pl.Prev.Nonemph Conj. 3P1.Postv.Nonemph money
The man has given you and them some money.

In (17a), a lexical noun and a 3rd plural postverbal pronoun are conjoined in the preverbal position, while in (17b) a 1st singular preverbal pronoun and a 2 nd plural postverbal pronouns are conjoined in a preverbal position. In (17c) a 2 nd plural preverbal pronoun and a 3rd plural postverbal pronoun are conjoined in a postverbal position.

Purvis (2007) argued that the correct forms of the pronouns, given the pre/ post verbal predictions about Dagbani personal pronouns, should be *[Adam mini be] in (17a), *[N mini yi] in (17b), and *[ya mini ba] in (17c). Nonetheless, these forms are unattested in the language. Based on this, Purvis (2007) maintained that the pre/post verbal distinction, as far as the distribution of the nonemphatic 
pronouns is concerned, is problematic. However, what Purvis failed to notice is the fact that, even in such coordinate structures, the postverbal form is always the second element. What this means is that the postverbal nonemphatic forms can never occur as the first conjunct of a conjunction structure, as illustrated in (17c). This data shows that there is a structural constraint imposed on the pronouns even in a conjunction structure, such that the postverbal forms can only occur after the conjunction marker, as shown in (18).

(18) More coordinate constructions with nonemphatic pronouns

[n mini ba] 'I and them'

[be mini ya] 'they and you (P1.)'

[n mini li] 'I and it'

[yi nimi ba] 'you and them'

* [ba mini ya] 'them and you'

*[yi mini di] 'you (P1.) and it'

*[n mini di] 'I and it'

My argument is that two postverbal forms cannot be coordinated, for example *[ba mini ya], 'them and you', and *[ya mini li], 'you and it'. Also, in a coordinate structure with two personal pronouns, the first pronoun must be a preverbal form, while the second is a postverbal form, as in [be mini ya], 'they and you', [ yi mini ba], 'you and them', and [n mini li] 'I and it'. Furthermore, two preverbal forms cannot also be coordinated in the same structure, as in $*[\mathbf{m} \mathbf{m i n i} \mathbf{b \varepsilon}]$, or $*[\mathbf{y i}$ mini di]. Based on these patterns, I propose that the conjunction construction has a structure, as shown in (19), which may impose some constraints on how the pre/ post verbal nonemphatic pronouns should be combined in a coordinate structure.

(19) Conjunction phrase structures
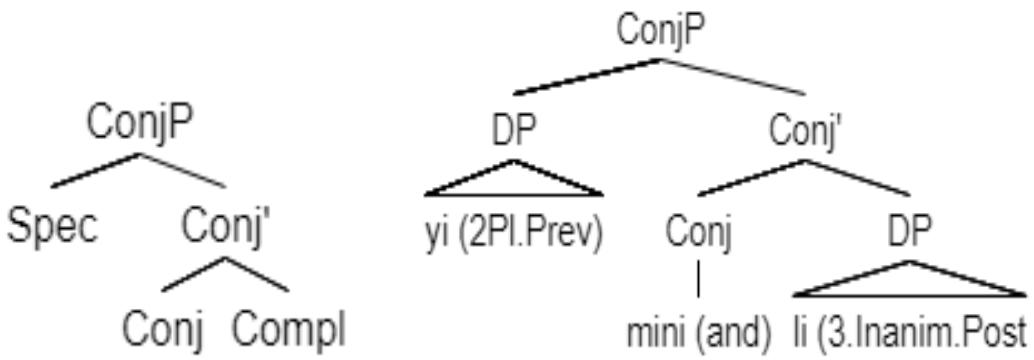
With respect to the nonemphatic pronouns, I propose tentatively that the Spec of ConjP is occupied by preverbal pronouns, and the Compl of ConjP is occupied by the postverbal pronouns. Then, Spec-head agreement restricts the preverbal forms to the first position of the conjunction structure. The assumption is that it is this co-occurrence restriction that makes it possible for a preverbal pronoun in a coordinated DP (either a lexical noun and pronoun, or two pronouns) to occur in both pre and postverbal positions in sentences, especially with the socalled "preverbal pronouns in postverbal positions", as observed by Purvis (2007).

Comparing the behaviour of both emphatic and nonemphatic pronouns in Dagbani with respect to conjunction, I will say that Dagbani pronouns differ from the personal pronouns of Romance and Germanic languages, in that the deficient (weak and clitic) pronouns in the latter languages cannot occur in coordinated structures. In addition to this, in Romance and Germanic languages, when strong pronouns occur in coordinate structures, they cannot refer to human entities which, again, make them different from Dagbani personal pronouns since, in Dagbani, coordinated emphatic pronouns can refer to human entities.

\section{Modifying Dagbani personal pronouns}

In terms of modification, both emphatic and nonemphatic personal pronouns can be modified with quantifiers. However, the kinds of modifiers they take can differ slightly. In the case of emphatic pronouns, their truncated forms are what surface during modification, a phenomenon which is common among lexical nouns in the language (see Hudu, 2005, for details). The quantifiers that can modify personal pronouns are presented in (20). However, note the difference in form between [-kam] and the rest of the modifiers/quantifiers. [-kam], 'every', appears as a bound form, while [zaa], 'all', [gba], 'also', and [ko/kokko], 'alone/only', are all free forms which can modify both lexical and pronominal forms. By way of illustration, (21)-(22) demonstrate how emphatic and nonemphatic pronouns are modified with these quantifiers/modifiers in Dagbani.

(20) Some quantifiers in Dagbani

(a) zaa 'all'

konko/ko 'only, alone'

gba 'also'

sheba/ sheya 'some'

pam 'many/much' 
(b) -kam 'every'.

sokam, 'everybody',

shelikam 'everything'

yinokam 'everyone'

(21) Emphatic pronouns and modification

(a) yun ko/konko, gba 'he/she only/alone, also'

man ko/konko, gba 'I only/alone, also'

nyin ko/konko, gba 'you only/alone, also'

din ko/konko, gba, kam 'it only/alone, also', everything'

(b) ben zaa, ko/konko, gba, sheba 'they all, only, also, some of them'

tinim zaa, ko/konko, gba, sheba 'we all, only, also, some of us,

yinim zaa, ko/konko, gba, sheba 'you all, only, also, some of you'

dinnim zaa, ko/konko, gba, sheya 'it all, only, also, some of it'

From (21a) we can see that the singular forms of emphatic pronouns can be quantified with [konko], 'alone', and [gba], 'also', whereas the plural forms of emphatic pronouns can take [zaa,], 'all', [ko/konko], 'only/alone', [gba], 'also', and [sheba/sheya], 'some'. When a singular emphatic pronoun is quantified with [zaa], as in [nyin zaa m-bala], 'you all that' which means [that is all of you], it indicates limited ability or possession. For instance, during a conversation, if Azima says to Dokurugu, [nyin zaa m-bala], then what Azima meant is that Dokurugu has no further ability or has nothing more to offer/show in relation to whatever they were talking about. In addition, plural nonemphatic pronouns can take [yino], 'only/alone', as a quantifier, but emphatic pronouns cannot co-occur with [yino], 'only/alone', as shown in (22). [yino] has a singular number interpretation, which might suggest that there is a co-occurrence restriction between the plural emphatic pronouns and the quantifier, as shown in (22b)), but this restriction does not seem to apply between plural nonemphatic pronouns and [yino], as illustrated in (22a).

(22) Non-emphatic pronouns and quantifiers

(a) ti yino (1P1.Nonemph only) 'one of us' yi yino (2P1.Nonemph only) 'one of you' be yino (3Pl.Anim.Nonemph only) 'one of them' di yini (3P1.Inanim.Nonemph only) 'one of it' 
Abukari, K./Legon Journal of the Humanities Vol. 30.2 (2019)

(b) *tinim' yino (1P1.Emph only) 'one of us'
*yinim' yino (2P1.Emph only) 'one of you'
*bannim' yino (3P1.Emph only) 'one of them'
*dinnim' yino (3P1.Inanim.Emph only) 'one of it'

Again, when it comes to preference, using nonemphatic pronouns with quantifiers and modifiers seem natural and is likely preferred over emphatic pronouns in some discourse contexts, which could suggest that there may be less restriction on nonemphatic pronouns and quantifiers. However, this is not actually the case, because postverbal nonemphatic pronouns cannot occur with quantifiers at all, except when they occur in coordinate structures. Nevertheless, the data shown in (20)-(22) indicates that, unlike the deficient pronouns in Cardinaletti and Starke's study, both emphatic and preverbal nonemphatic Dagbani pronouns can take quantifiers as modifying elements. Cardinaletti and Starke's typology showed that only strong pronouns and lexical nouns can be modified in Romance and Germanic languages.

Also, Purvis (2007) observed that when nonemphatic pronouns are quantified, the pre/post verbal distinctions disappear. In relation to that, I propose that the quantifier phrase (QP), as shown in (23), has a structural imposition which makes Purvis' observation possible.

(23) The structure of a quantified DP

(a)
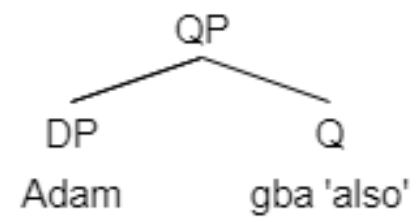

yi (you) zaa (all)

y (I) konko (alone)

be (they) pam (many)

*ma (I) gba (also)

(b) A quantified conjunctive DP 
Abukari, K.The Syntax of Dagbani personal pronouns: an analysis

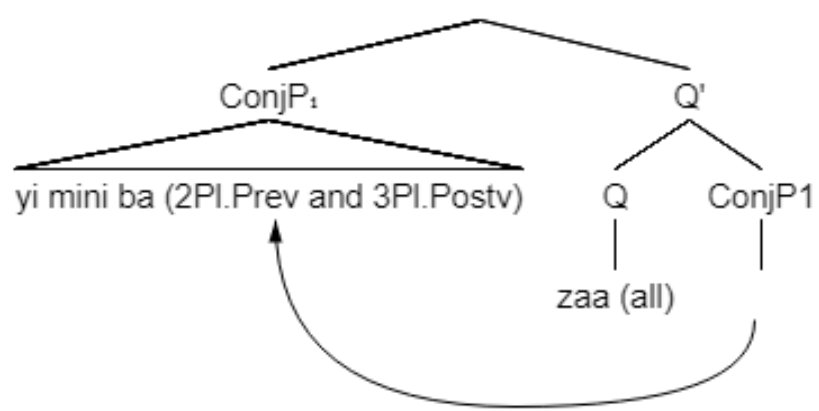

(c) Conjunction has scope over the quantifier

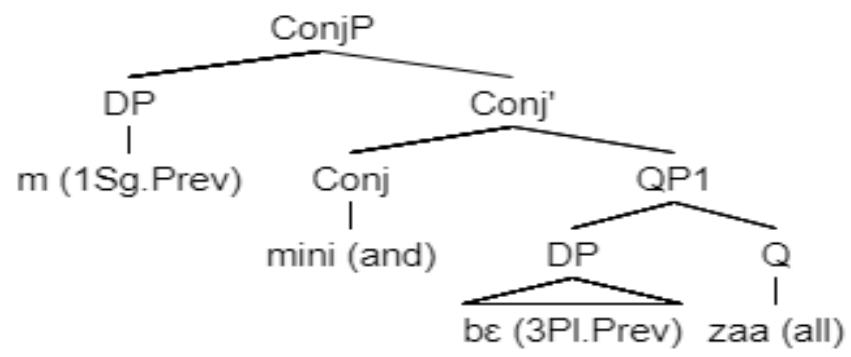

Given the above structures ( $23 \mathrm{~b}$ and $\mathrm{c}$ ), and like the conjunction structure, the quantifier phrase also has a structural restriction where only the preverbal pronouns occur with the quantifier in both pre and postverbal positions in sentences. In (23b), the quantifier has scope over the coordinate structure and will be read as I[yi mini ba] zaa], whereas in (23c) the quantifier has scope over only the 3rd person preverbal pronoun and will be read as [m mini [be zaa]], as detailed in (24).

(24) Combining conjoined structures with quantifiers in Dagbani

(a) $\left[\begin{array}{llll}\mathrm{m} & \text { mini ba } & \text { zaa }] \text { ni chan yina }\end{array}\right.$ 1Sg.Nonemph Conj 3Pl.Nonemph.Postv all Fut go home I and they all will go home. (I together with them [all of us] will go home)

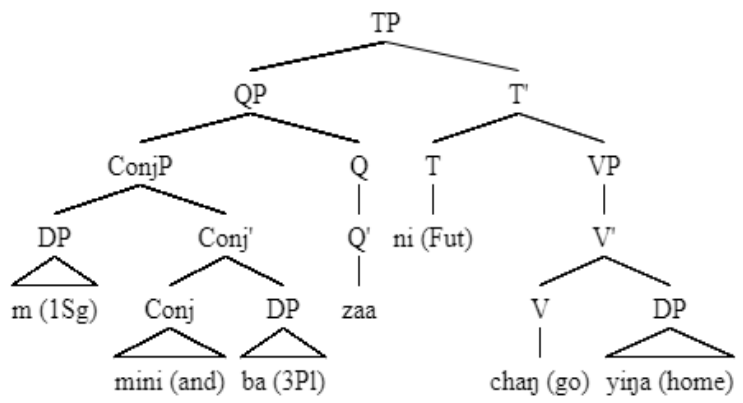


(b) $[\mathrm{m} \quad \operatorname{mini}[\mathrm{b} \varepsilon \quad$ zaa $]]$ ni chay yina. 1Sg.NonEmph Conj. 3Pl.Non-Emph.Prev all Fut go home I and they all will go home (I and all of them will go home).

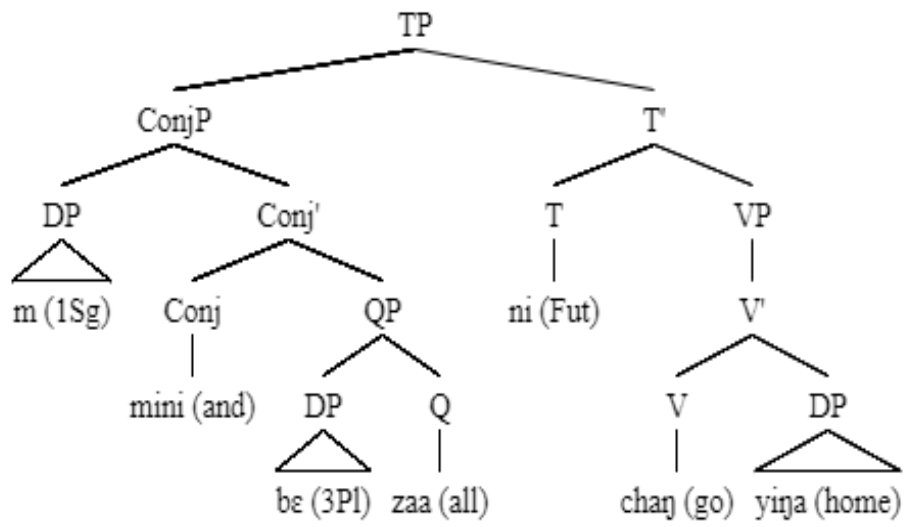

In (24a) the quantifier has scope over the entire conjunction structure, as shown in the tree diagram below the sentence, hence, the 3rd person plural nonemphatic pronoun being inclusive in the conjunction structure. However, in (24b), the quantifier has scope over only the 3rd person plural pronoun, as also shown in the tree diagram. This means that the quantifier, 'all', only relates to [be], 'they'. This suggests that, like the conjunction markers, a quantifier phrase must have a certain structure that makes it possible for the preverbal nonemphatic pronouns to occur in both pre and postverbal positions, when they occur in a quantifier phrase. Otherwise, without any quantifier, the pre/post verbal distinction will remain, as shown in the discussion on "Preverbal forms in post-verbal position and vice versa", as well as in (25).

(25) Dagbani nonemphatic pronouns and quantifiers

(a) Akonsi puhi-Ø $[* \mathrm{ba} / \mathrm{b} \varepsilon$ zaa $]$ vicnyela.

Akonsi greet-Perf 3P1.Postv/Prev.Nonemph all properly

Akonsi greeted all of them properly/very well.

(b) Adam puhi- $\varnothing *$ be/ba vienyela.

Adam greet-Perf 3P1.Prev/Postv.Nonemph well

Adam greeted them properly/very well.

(c) $\quad$ di zaa $] \mathrm{ka}$ o da- $\varnothing$.

3P1.Inanim.Nonemph all Foc 3Sg.Nonemph buy-Perf 
It was all of it (that) he bought. (di is in focus here)

In (25a) we have a preverbal form of the pronoun occurring in a postverbal position with the quantifier to form [be zaa]. The occurrence of [ba] in such a context is illicit, since it cannot take a quantifier. However, in (25b), the postverbal form of the pronoun [ba] is used instead of $[\mathbf{b \varepsilon}]$ due to the absence of the quantifier. Further, in $(25 \mathrm{c})$ a preverbal form occurs, quantified in the postverbal position, and is moved to the preverbal position, as signalled by the focus maker [ka] in the construction. The underlying form of $(25 \mathrm{c})$ is [o da- $\varnothing$ di zaa], 'he/she bought all of it'. The constituent, [di zaa], is then moved to the initial position in the sentence and becomes focused, as shown in (25c). My argument is that all the postverbal forms, [ba, ya, ma, li], of the nonemphatic pronouns cannot occur with quantifiers, therefore they will always be postverbal in sentences.

Lastly, it is also important to note that it is common for native Dagbani speakers to combine both singular and plural nonemphatic pronouns, as well as lexical nouns, with [gba zaa], as in [n gba zaa], 'I also', [ti gba zaa], 'we also', etc. In such structures, especially where the pronoun/lexical noun is singular, [zaa] may pragmatically function as an emphasizer rather than a quantifier.

\section{Dagbani personal pronouns and topic/focus encoding}

The concepts of topic and focus are important discourse notions which add to the semantic enlightenment and interpretation of conversational exchanges (Kaiser, 2005; Krifka, 2008; Zimmermann \& Onea, 2011). The topic in a discourse relates to what is being talked about in an information structure, which can be the same as the grammatical subject, or not. Kaiser (2005) observed that subjecthood, givenness, and pronominalization can all increase the topicality of a referent in a discourse. Topics in sentences can be located at the left periphery, under the CP layer, as well as sometimes at the right edge of a sentence, constituting the entity in a clause or sentence to which the rest of the clause or sentence is about (Rizzi, 1997).

Focus, on the other hand, is a salient discourse feature which contributes new, contrastive, or non-derivable information in a discourse. ${ }^{3}$ Pragmatically, it is the most salient element in a sentence. Focus is also conceived of as indicating the presence of alternatives in discourse, which are important for the interpretation of given linguistic expressions (Zimmermann \& Onea, 2011; Krifka, 2008). Focus can be expressed morpho-syntactically, prosodically, or both, and can be signalled in discourse through intonation, pitch accent, or stress (Krifka, 2008; Zimmermann \& Onea, 2011). Kiss (1998, pp. 245-246) observed that contrastive

\footnotetext{
${ }^{3}$ Krifka (2008, p. 257), however, suggested that conceiving focus as that which signals importance, newness, or presupposition of existence need not figure in the definition of focus. To Krifka, the basic notion of focus should be about indicating the presence of alternatives for interpretation in the common ground management space.
} 
focus (identificational focus) expresses exhaustive identification, and involves syntactic reordering, while presentational focus (information focus) merely conveys new nonpresupposed information without expressing exhaustive identification. Contrastive focus is an operator with features [+exhaustive, +contrastive] and has binding effects, whereas presentational focus is present in every sentence and has no scope (Kiss, 1998).

Focus markers and focus constructions in Dagbani have been studied extensively, where [la], [ka], and [n] are identified as morphological focus makers in Dagbani (Hudu, 2012; Issah, 2008, 2012; Schwarz, 2005; Issah \& Smith, 2018). However, there are some disagreements among researchers concerning the staus of $[\mathbf{l a}]^{4}$, the postverbal focus marker in Dagbani. Scholars have agreed that [la] is a focus marker, but they disagree on its ability to establish contrastive focus.

Turning to the behaviour of Dagbani personal pronouns in relation to topic and focus, the following are my observations based on previous studies, as well as my intuition as a native speaker. In Dagbani, emphatic personal pronouns can function as topics in sentences or in discourse, and in some contexts, nonemphatic pronouns may also occur as topics. In (26), the pronouns function as topics.

(26) Dagbani personal pronouns and topic/focus encoding
(a)
yuni $n$
n
bi-hi
maa?
who Foc insult-Perf
child-Pl
Def
who insulted the children?
(b) $*$ n/mani/Adam
1Sg.Nonemph/1Sg.Emph/Lexical noun
I/Adam (I insulted the children/ADAM insulted the children
(c) mani, man' n- me dimboyo zaa.(Purvis, 2007, p. 241) 1Sg/Emph 1Sg/Emph Foc build.Perf Dem all
'Me, [It is] I [who] built all these.' (Disjoint, Emphasis. Subject.)

The question in (26a) is in the context of focus and thus requires an answer that is in focus. This answer, provided in (26b), can be an emphatic pronoun or a lexical noun. Hence, the 1st singular emphatic pronoun [mani], or Adam can answer the question, but not the 1st person nonemphatic pronoun [n]. Also, in (26c), the emphatic pronoun [mani] is the topic, and the truncated form [man'] is the focus, as it is immediately followed by the focus marker [n], which Purvis glossed as an infinitive marker used for emphasis. In both (26b) and (26c), the emphatic pronoun [mani], 'I', is exhaustively identified from any other alternatives within the privileged possible worlds (PPWs), to use Zimmermann and Onea's (2011)

\footnotetext{
${ }^{4} \mathrm{Hudu}$ (2012) claims that [la] is a postverbal contrastive focus marker which focuses a noun, pronoun, or adjunct in the postverbal position. However, Issah $(2008,2012)$ thinks that [la] is just a presentational focus marker and not a contrastive focus particle. For details, readers can consult these references.
} 
conception of focus, that could undertake the activity of insulting or building.

In relation to nonemphatic pronouns and focus marking, I argue that nonemphatic personal pronouns can only mark a presentational focus of giving new information in a sentence, but not a contrastive focus, as shown in (27). Studies have even shown that weak pronouns are banned in a focus position and cannot be topicalized either (Agbedor, 1996; Grohmann, 2000).

(27) Dagbani pronouns in topic/focus positions

(a) bo ka Adam da-Ø?

what Foc Adam buy-Perf

What did Adam buy?

(b) loori pal-li ka Adam da-Ø.

Lorry new-Sg Foc Adam buy.

Adam bought a NEW LORRY.

(c)

*li $\quad$ ka

3Sg.Inanim.Nonemph.Postv Foc

Adam da- $\varnothing \quad$ zay'palli.

Adam buy-Perf one-new

Adam bought IT as new (It being focused here).

(d)

$\begin{array}{llll}\text { dina } & \text { ka } & \text { Adam da- } \varnothing & \text { zay'palli. } \\ \text { 3Sg.Inanim.Emph Foc } & \text { Adam buy-Perf } & \text { one-new }\end{array}$

It is it that Adam bought as new.

In the question in (27a), the object of the sentence is in a focused context. Therefore, the answer must also be focused. This explains why the answer, [loori palli],'a new lorry', is focused by preposing it to the sentence initial position where focus is signalled morphologically by the contrastive focus maker [ka], which mean that 'a new lorry' is exhaustively identified from other options (such as an old lorry or a slightly used lorry). When the DP [loori palli] is replaced with a pronoun, we get the 3rd person inanimate nonemphatic form [li], which cannot stand alone as an answer to the question. This implies that nonemphatic personal pronouns cannot bear contrastive focus, as doing so results in ungrammaticality in (27c). However, when [li] is replaced with an emphatic form, the ungrammaticality is resolved in (27d). The person uttering (27d) must also be pointing at the 'new lorry' (by ostension).

Strangely, however, it is possible to focus conjoined nonemphatic pronouns, as shown in (28), even though a single nonemphatic pronoun cannot be focused, as already demonstrated in (27c). Note that the coordinated nonemphatic pronouns which form a constituent are in square brackets. 
Abukari, K./Legon Journal of the Humanities Vol. 30.2 (2019)

(28) Conjoined nonemphatic pronouns bear contrastive focus

a. Munira ti- $\varnothing \quad[\mathbf{n}$ mini ba $]$ li?iri. Munira give-Perf 1Sg.Nonemph.Prev Conj. 3P1.Nonemph.Postv money Munira gave I and them money.

b. $[\mathrm{n} \quad \operatorname{mini}$ ba $] \quad$ ka Munira ti- $\varnothing$ li?iri.

1Sg.Nonemph.Prev Conj. 3Pl.Nonemph Foc Munira give-Perf money It was I and them that Munira gave money.

As can be seen in (28b), the coordinated nonemphatic pronoun is moved to the sentence initial position where it bears focus which is signalled by the focus marker [ka]. Without being in a conjunction structure, nonemphatic personal pronouns in Dagbani cannot bear focus.

Another observation is that quantified nonemphatic personal pronouns can also be focused. That is, when a nonemphatic personal pronoun is modified with a universal quantifier, such as [zaa], 'all', and [ko/konko], 'alone/only', then the pronoun can be focused in the sentence initial position, as shown in (29b), as well as become topicalized, (29c).

(29) Quantified nonemphatic personal pronouns and focus
(a)
Adamu
tu- $\varnothing$
[be
sheba].
Adamu insult-Perf
3Pl.Nonemph.Prev
some of them

Adamu insulted some of them.

(b) $\quad[\mathrm{b} \varepsilon$

sheba] ka Adamu

3Pl.Prev some of them Foc Adamu insult-Perf

tu- $\varnothing$.

Adamu insulted SOME OF THEM (as opposed to all of them).

(c) $\quad[$ yi

zaa], ninvu?-yo-ya $\mathbf{n}$ nya ya.

[2Pl.Prev.Nonemphatic all $]_{\mathrm{TOP}}$ person-bad-Pl Foc be 2P1.Postv

You, you are ALL CRIMINALS (All of you are criminals)

In summary, emphatic pronouns in Dagbani can serve as topics as well as occur in focused contexts. This observation about Dagbani emphatic pronouns concerning their ability to encode focus or topic makes them pattern with the behaviour of strong pronouns in Cardinaletti and Starke's (1994) study. Nonemphatic pronouns can only occur in focus or topic positions when they are modified by quantifiers or coordinated with other pronouns or lexical nouns.

\section{Towards a syntactic account of pronoun coordination/modification}

In this section, I attempt to account for some of the observations made earlier in the paper. I draw insights from the studies of Agbedor (1996), Grano (2006), and Grohmann (2000). 
In a study on personal pronouns in English using both corpus and experimental data, Grano (2006) noted interesting findings on pronoun coordination in English. Although frequency of use, the impact of prescriptive grammar, and other pragmatic factors (e.g., forms considered to be prestigious) were found to be relevant, Grano's (2006) Pronoun Linear Precedence (PLP) Constraints, as in (30), is of much importance in this paper, especially those that are bolded.

(30) Pronoun Linear Precedence (PLP) Constraints (Grano, 2006, p. 40)

1. "X and I": [anything] $<$ I

2. Lexical Status: pronoun $<$ full-NP

3. Case: nominative $<$ accusative

4. Person: $2<\mathbf{1}<\mathbf{3}$

Where 1 is first and 3 is third person singular pronouns in English.

Grano (2006) explained that under the PLP, the constraint " $X$ and $I$ " ranks highest, and means that anytime the pronoun " $I$ " is involved in a coordinate structure, it will be ordered second. Between a pronoun and a full-NP, a pronoun will tend to precede a full-NP whenever there is no " $I$ ". And when neither "I" nor a full-NP is involved, a nominative pronoun will tend to precede an accusative one. Finally, if none of these constraints apply, then a 2 nd person pronoun will tend to precede a 1 st person pronoun, and a 1 st person pronoun will tend to precede a $3 \mathrm{rd}$ person pronoun.

In exploring these constraints among coordinated Dagbani nonemphatic pronouns, it will be argued that the " $X$ and $I$ " constraint is independently ruled out in Dagbani based on the data presented in (31).

(31) Coordinating Dagbani nonemphatic pronouns and Grano's (2006) PLP Constraints

\section{(a) [X and 1]}

*[di mini n] '3Sg.Inanim and $1 \mathrm{Sg}$ '

[n mini ya] ' $1 \mathrm{Sg}$ and $2 \mathrm{Pl}$ '

[n mini ba] ' $1 \mathrm{Sg}$ and $3 \mathrm{Pl}$ '

*[yi nimi $\mathrm{ma}$ ] '2Pl and $1 \mathrm{Sg}$ ' (b) [pronoun $<$ full-NP]

[n mini Azima] '1Sg and Azima'

[yi mini Azima] '2Pl and Azima'

[be mini Azima] '3Pl.Anim and Azima'

[di mini Azima] '3Sg.Inanim and Azima'

(c) $[$ Nom. $<$ Acc. $]$

[n mini li] '1Sg.Prev and 3Sg.Inanim.Postv'

[m mini ya] '1Sg.Prev and 2Pl.Postv'

[be mini li] '3Pl.Anim.Prev and 3Sg.Inanim.Postv'

* [ba mini ya] '3Pl.Anim.Postv and 2Pl.Postv

In this data, the "Nom. < Acc." constraint would be the highest ranked in Dagbani (see (31c)), since in (31a) there are no attested forms that obey the coordination constraint " $X$ and 1 ". Also, the pronoun-before-full-NP constraint would be applicable in Dagbani (31b), since the form *[Azima mini ma], is ruled 
out, along with any coordination structure in which the second conjunct is a singular 1 st person pronoun, although full-NPs may precede 2 nd and $3 \mathrm{rd}$ person pronoun forms. In terms of person ordering, Dagbani follows an order of $1<2<3$ or $1<2=$ 3 , since both 2 nd and 3 rd person pronouns can be coordinated, with either of them occurring as first or second conjunct, even though the 2 nd person pronoun being the first conjunct would seem more natural. For example, in $2<3$ order, we can have [a mini o], '2Sg and $3 \mathrm{Sg}$ ', [yi mini ba], '2Pl and $3 \mathrm{Pl}$ ', and [yi mini li], ' $2 \mathrm{Pl}$ and $3 \mathrm{Sg}$ '. Whereas in $3<2$ order, we can have [o mini a], ' $3 \mathrm{Sg}$ and $2 \mathrm{sg}$ ', [di mini o], ' $3 \mathrm{Sg}$ and 2Sg', [di mini ya], '3Sg and 2Pl', and [be mini ya], '3Pl and 2Pl.

Therefore, with the notion of "preverbal pronouns in postverbal position" and vice versa, the constraints regulating that, according to Grano's (2006) PLP, will be "Nom. < Acc.", which would further place Dagbani in Pattern III of Grano's (2006, p. 49) pronoun case-marking typology, where coordinated pronouns are "Nom. < Acc." both in subject and in object positions, which I take to be pre and postverbal positions, respectively. Concerning the quantifier modification, it could be argued that in Dagbani, only the "Nom." pronominal forms may occur with quantifiers. Considering these observations, I propose that Dagbani nonemphatic pronoun distribution is influenced by case.

Based on Agbedor's (1996) analysis of weak pronouns in Ewe, the nonemphatic pronouns in Dagbani could be argued to be projected under IP where they are governed by INFL. Thus, avoiding complex syntactic processes, it could be stated that preverbal nonemphatic pronouns are generated at Spec IP and postverbal nonemphatic pronouns are the complement of the verb. Then, nominative and accusative cases are assigned to them, respectively. Furthermore, since Dagbani nonemphatic pronouns cannot bear contrastive focus and cannot stand alone as answer to a wh- question, they must be projected differently compared to emphatic pronouns, which behave like lexical nouns. Both emphatic pronouns and lexical nouns do not require case, and when they occur in focus contexts, they are usually followed by focus markers. In general, therefore, nonemphatic pronouns can only be projected under $\mathrm{CP}$ when they occur with a quantifier or in a coordinate structure, in which case they can also be focused or get topicalized in the syntax, as shown in (29c). Nonetheless, I leave this observation open for further research. 


\section{Summary and conclusion}

This paper investigated the syntax of Dagbani personal pronouns along Cardinaletti and Starke's (1994) typology. It also explored the notion of pre and postverbal categorization of Dagbani nonemphatic pronouns, which led to a few descriptive generalizations about Dagbani personal pronouns. First, all emphatic pronouns in Dagbani can occur in both pre and postverbal positions. The nonemphatic pronouns, on the other hand, have some syntactic distributional restrictions in sentences. Previous notions that some are preverbal while others are postverbal is supported. However, when nonemphatic pronouns occur in conjunction or quantifier constructions, some combinatorial restrictions are imposed, making preverbal forms to always occur as the first pronoun, and postverbal forms as the second pronoun. In such structures, the so-called "preverbal forms in postverbal positions" and vice versa are plausible. Additionally, whereas emphatic pronouns can bear contrastive focus, nonemphatic pronouns can only bear contrastive focus when modified by quantifiers or when they occur in conjunction structures. Dagbani nonemphatic pronoun distribution is also argued to be influenced by Grano's (2006) PLP Constraints and pronoun case-marking typology.

Based on Cardinaletti and Starke's (1994) typology, Dagbani personal pronouns differ in several ways. On the one hand, unlike in Romance and Germanic languages, both emphatic and nonemphatic personal pronouns in Dagbani can be coordinated. They can also be modified by quantifiers. On the other hand, as in Romance and Germanic languages, there is a minimal containment relationship between the plural emphatic and plural nonemphatic pronouns in Dagbani, and only emphatic pronouns can be focused or topicalized.

Due to the behaviour of the nonemphatic pronouns with conjunctions and quantifiers in the language, I propose that further research is needed to fully explore the nonemphatic pronouns in quantifier and conjunction phrases, as functional projections in Dagbani. In conclusion, I observe that Romance and Germanic languages' pronouns and Dagbani pronouns have little in common with regards to their morphosyntactic behaviour. 


\section{Abbreviations}

1, 2, 3: first, second and third persons respectively; Anim. - animate; Def - definite determiner; Dem - demonstrative; Conj. - conjunctive marker; Emph. emphatic pronoun; Foc - focus marker; Fut. - Future marker; Imperf - imperfective aspect; Inanim. - inanimate; Loc. - locative marker; NEG - negative particle; Nonemph. - nonemphatic pronoun; Num-Root - number root; Perf - perfective aspect; P1 - plural; Q - quantifier; QP - quantifier phrase; Sg - singular; Prev. preverbal; Postv. - post verbal; ConjP. - Conjunctive phrase

\section{Acknowledgment}

I express my appreciation to the anonymous reviewers and the Journal administrator for their valuable comments and suggestions that helped to improve the analysis presented in this paper. I also thank Miss Sarah Caufield for proofreading the paper and making beneficial suggestions. All remaining errors are mine. 
Abukari, K.The Syntax of Dagbani personal pronouns: an analysis

\section{References}

Abels, K. and Muriungi, P. (2008). The Focus marker in Kiitharaka: Syntax and Semantics. Lingua, 118, 687-731.

Agbedor, P. (1996). The syntax of Ewe personal pronouns. Linguistique Africaine, $16,19-51$.

Bodomo, A. (1993). Complex predicates and event structure: An integrated analysis of serial verb constructions in the Mabia languages of West Africa. Master's thesis. Trondheim: University of Trondheim. Working Papers in Linguistics, no. 20.

Cardinaletti, A. \& Starke, M. (1994). The Typology of Structural Deficiency: On the Three Grammatical Classes. University of Venice Working Papers in Linguistics, 4(2), 41-110.

Grano, T. (2006). "Me and her" meets "he and I": Case, person, and linear ordering in English coordinated pronouns. (Honors Thesis). California: Stanford University.

Grohmann, K. K. (2000). Towards a Syntactic understanding of prosodically reduced pronouns. Theoretical Linguistics, 26(3), 175-210.

Hudu, F. (2005). Number marking in Dagbani. Thesis. Alberta: University of Alberta.

Hudu, F. (2010). Dagbani tongue-root harmony: A formal account with ultrasound investigation. (PhD dissertation). University of British Columbia, Canada. British Columbia.

Hudu, F. (2012). Dagbani focus particles: A descriptive study. Journal of West African Languages, XXXIX(1), 97-129.

Issah, S. A. (2008). Information Packaging in Dagbani, MPhil Thesis. Tromso: University of Tromso.

Issah, A. S. (2011). Reflexive pronouns in Dagbani. Legon Journal of the Humanities, 22, 129-146.

Issah, A. S. (2012). Phrasal identification and contrastive focus in Dagbani. Journal of West Arfican Languages, XXXIX(1), 75-96.

Issah, A. S. (2013). The structure of the Dagbani simple noun phrase. South African Journal of African Languages, 33(2), 203-212.

Issah, A.S. \& Smith, P.W. (2018). Subject and non-subject ex-situ focus in Dagbani. Goethe-Universität, Frankfurt, 1-38. 
Kaiser, E. (2005). Effects of topic and focus on salience. In Chritian, E. \& Coenelia, E. (Eds.) Proceedings of the Sinn und Bedeutung 10th annual meeting of the Gesellschaft für Semantik, 1, 139/154.

Kiss, E. K. (1998). Identificational focus versus infromation focus. Language, 74(2), 245-273.

Krifka, M. (2008). Basic notions of information structure. Acta Linguistica Hungarica, 55(3-4), 243-276. doi:10.1556/ALing.55.2008.3-4.2

Olawsky, J. K. (1999). Aspects of Dagbani grammar: with special emphasis on phonology and morphology. Munich: Lincom.

Olawsky, J. K. (2002). What is a word in Dagbani? In Dixon R.M.W. \& Aikhenvald, A.Y. (Eds.). Word: A Cross-Linguistic Typology. Cambridge: Cambridge University Press.

Purvis, M. T. (2007). A reanalysis of non/emphatic pronouns in Dagbani. In Frederick Hoyt et al.( Eds.) Texas Linguistics Society IX: The Morphosyntax of Underrepresented Languages, 239-263.

Rizzi, L. (1997). The fine structure of the left periphery. In Haegeman. L. Elements of Grammar: Handbook in generative syntax (pp. 281-337). Dordrecht, Netherlands: Kluwer.

Schwarz, A. (2005). Copulative and Narrative Patterns in Gur Focus Constructions. Gur Conference "Between tone and text", 12-14 October 2005, Bayreuth, (pp. 1-9). Bayreuth.

Zimmermann, M. \& Onea, E. (2011). Focus marking and focus interpretation. Lingua, 121, 1651-1670. doi:10.1016/j.lingua.2011.06.002 